\title{
Pancreatic Intraductal Neoplasm
}

National Cancer Institute

\section{Source}

National Cancer Institute. Pancreatic Intraductal Neoplasm. NCI Thesaurus. Code C95505.

A group of cystic or mass-forming epithelial neoplasms that arise from the exocrine pancreas, exhibit ductal differentiation, and grow mostly within the pancreatic ducts. This group includes the pancreatic intraductal papillary mucinous neoplasms and the pancreatic intraductal tubulopapillary neoplasms. 